\title{
Development of an objective and uniform scoring method to evaluate the quality of rearing in Dutch dairy herds
}

\author{
I. M. G. A. Santman-Berends, ${ }^{* 1}$ H. Brouwer, ${ }^{*}$ A. ten Wolthuis-Bronsvoort, ${ }^{*}$ A. J. G. De Bont-Smolenaars, ${ }^{*}$ \\ S. Haarman-Zantinge, ${ }^{*}$ and G. Van Schaik*† \\ ${ }^{*}$ GD Animal Health, PO Box 9, 7400 AA Deventer, the Netherlands \\ †Department of Farm Animal Health, Faculty of Veterinary Medicine, Utrecht University, PO Box 80151, 3508 TD Utrecht, the Netherlands
}

\begin{abstract}
Young stock rearing is an essential part of dairy management, and it is important that the quality of rearing can be monitored and altered if necessary. In this study, a young stock rearing quality system (KalfOK) was developed with the aim to provide an objective and standardized means to evaluate and monitor the quality of young stock rearing in Dutch dairy herds. In the project, 201 dairy farmers participated. Twelve key indicators were defined that were related to calving and successful rearing, antimicrobial use, and herd health. For each of the key indicators, the value was calculated per herd and quarter of the year between January 2014 and April 2017. Benchmark values were determined to compare herd-specific results and for selection of threshold values. Each of the key indicators was graded when the value scored above the threshold. Combining the grades resulted in the herd-specific KalfOK score, which could vary between 0 and 100. Subsequently, 100 of the participating dairy herds were visited and the quality of young stock rearing was scored by a trained veterinarian. Using principal component analysis, the results of the herd health checks were combined into a factor score that represented the observed quality of young stock rearing during the visit. The amount of variance in observed quality of rearing during the herd health check that was explained by the key indicators in KalfOK was evaluated. Additionally, the validity of KalfOK to distinguish herds with an excellent or insufficient quality of young stock rearing was assessed by comparing the top and bottom $10 \%$ herds in the herd health check with the proportion of herds with a KalfOK score above or below a prespecified cutoff value. The results of the linear regression model showed that
\end{abstract}

Received January 16, 2018.

Accepted May 9, 2018.

${ }^{1}$ Corresponding author: i.santman@gdanimalhealth.com the key indicators included in KalfOK accounted for $56 \%$ of the variation in the score of the herd visits by a veterinarian. The moving average of the annual KalfOK score, which was the sum of the grades of all key indicators, was 77 points (25th percentile $=71$, 75th percentile $=85$ points). The combination of the sensitivity $(88 \%, 95 \%$ confidence interval $=47-100 \%)$ and specificity $(67 \%, 95 \%$ confidence interval $=54-78 \%)$ of KalfOK to correctly classify herds with an excellent quality of young stock rearing was highest when a cutoff value of 80 points was applied. Detection of dairy herds with an insufficient quality of young stock rearing was best at a cutoff value of 70 points (sensitivity $86 \%, 95 \%$ confidence interval $=42-100 \%$; specificity $77 \%, 95 \%$ confidence interval $=66-86 \%$ ). The KalfOK score that was based on routinely collected herd data provided an indication of the quality of young stock rearing in individual Dutch dairy farms. The KalfOK score illustrates how such data can be transferred into herd-specific information in support of animal health and welfare. Given the increasing availability of automatically assembled data, the development of similar monitoring tools seems a feasible option to enhance herd-specific management.

Key words: dairy calves, young stock, rearing management

\section{INTRODUCTION}

Young stock rearing is an essential part of dairy management given that calves are raised as replacement for milking cows. A faster growth rate during the first 6 mo of life results in a younger age at first calving and a higher productivity as milking cow (Ettema and Santos, 2004; Hultgren and Svensson, 2009). An important indicator of the quality of rearing is the calf mortality rate (Ortiz-Pelaez et al., 2008; Kelly et al., 2013). A higher mortality rate in young calves is known to be associated with poorer young stock rearing practices and results in a deterioration of animal welfare (Sandgren et al., 2009; de Vries et al., 2011). Previous studies showed 
that purchase of cattle, a larger herd size, disease status at the herd level, and not using separate housing for sick calves were associated with a higher calf mortality and a subsequently lower health and welfare during the rearing period (Santman-Berends et al., 2014; SeppäLassila, et al., 2016). One of the general recommendations of those studies was that tailored management advice at individual herd level was needed to improve the quality of rearing (Santman-Berends et al., 2014; Seppä-Lassila, et al., 2016; Van Eetvelde and Opsomer, 2017). Santman-Berends et al. (2014) also concluded that a lack of knowledge about calf health indicators exists among farmers. Farmers were frequently unaware of performance indicators such as calf mortality in their own herd and whether it was high or low compared with other herds. Therefore, a need exists for supporting tools for dairy farmers to stimulate improvement of the quality of young stock rearing. These tools should inform farmers and their veterinarians about the performance of their calves compared with a benchmark of colleagues. Insight in detailed aspects of young stock rearing should provide guidance where to adapt the rearing management to improve calf and young stock health.

The aim of our study was to develop a young stock rearing quality system (KalfOK) that provides insight in the performance of key indicators with regard to the quality of young stock rearing in the individual herd. Prerequisites were that the key indicators could be calculated based on routinely collected data, that the selected key indicators were associated with calf and young stock health and rearing, that the system was easy to use and understandable for farmers, and that it would result in a tool that was informative and would reveal both the strengths and weaknesses in the herd-specific young stock rearing management.

\section{MATERIALS AND METHODS}

In this study, young stock rearing was defined as the period between birth and moment of first calving and was stratified into 4 different time periods. (1) The perinatal period included calves from the moment of birth until ear-tagging. In the Netherlands, farmers are allowed to ear-tag their calves at an age of at most $3 \mathrm{~d}$ old. In general, calves are about $24 \mathrm{~h}$ old at moment of ear-tagging. (2) The postnatal period of young calves began the moment of ear-tagging up to $14 \mathrm{~d}$ of age. In the Netherlands, it is prohibited to move calves offfarm for live trade before $14 \mathrm{~d}$ of age. (3) The second postnatal period of calves was from $15 \mathrm{~d}$ of age until 56 d of age (moment of weaning). (4). The final period in which older calves were followed was from $56 \mathrm{~d}$ up to young stock of $2 \mathrm{yr}$ of age.

\section{Study Population}

In August 2016, 1,200 randomly selected dairy farmers were contacted with the request to participate. Criteria for participation were (1) that the farmer allowed the researchers to use routinely collected data from the herd for the development of the tool and (2) that they agreed with a possible herd visit by a veterinarian, during which the quality of young stock rearing was scored for validation purposes of KalfOK. Participants were asked for feedback during the study and an incentive for participation was that they would receive their herd-specific KalfOK report once the tool was finished. The herds of the first 201 responders were included in the study, from which 31 outsourced their calf young stock rearing. These 201 dairy herds comprised $1.2 \%$ of the total Dutch dairy population. It was expected that a group of more than 200 herds would have sufficient variation in quality of young stock rearing to enable development of a valuable evaluation tool. From these young stock raisers, additional agreement for participation was obtained and a combination of a dairy herd and its young stock rearing herd were considered 1 epidemiological unit.

\section{Available Data}

From each of the participating herds, routinely collected data were available from 5 different data sources from January 1, 2014, until March 31, 2017. Registrations on animal movements were available from the identification and registration system (I\&R, RVO Assen, the Netherlands), in which each animal and its movements between Dutch cattle herds are registered. Mortality records were available for perinatal calves, postnatal calves (up to $1 \mathrm{yr}$ of age), and older cattle from the rendering plant (Rendac, Son, the Netherlands). The herd health status for infectious bovine rhinotracheitis (IBR), bovine viral diarrhea (BVD), Salmonella, neosporosis, paratuberculosis, and mineral status of the bulk milk were available from GD Animal Health (Deventer, the Netherlands) and medicine use was obtained from the MediRund data system (ZuivelNL, The Hague, the Netherlands).

Dutch veterinarians are obliged to register all supplies of antimicrobials in the MediRund system. Nevertheless, most veterinarians automatically register all other medicines and vaccinations that they supply to farmers as well. As part of this project, all participants were requested to deliver an overview describing the medicines that they had applied in their preweaning calves between July 1, 2015, and June 30, 2016. In addition, the veterinary registrations in MediRund were available during the same period to evaluate whether 
the quality of medicine registrations in MediRund (other than antimicrobials) was similar to those registered by the farmer and was sufficient to be incorporated in KalfOK.

\section{Key Indicators and Development of the KalfOK Score}

A large number of key indicators were developed that (1) could be calculated based on routinely collected data, (2) were known to be associated with young stock rearing and health according to literature, and (3) could be calculated for all dairy herds (i.e., census data). Thus, for example, fertility parameters that were available for part of the dairy herds $(\approx 75 \%)$ were not used in the study. An expert team was assembled, containing 2 members of the project team (epidemiologist, a veterinarian, and zootechnical expert from GD Animal Health), 3 independent veterinary practitioners, and 2 participating farmers. The veterinary practitioners that were asked to participate in the expert team were officially recognized as specialists in young stock health and management. The 2 farmers were randomly selected from the study population. The list of initially developed key indicators together with their definitions was presented to the experts by means of a survey beforehand. Each individual expert was requested to rank the key indicators from high to low, in which the most important indicators for young stock rearing according to their opinion and expertise were scored highest and key indicators that were considered superfluous lowest. Additionally, the experts were also asked what they found most important in young stock rearing and if any key indicators were missing from the provided survey. During a subsequent expert workshop, 3 groups of key indicators for young stock rearing were defined, and within each group several key indicators that received the highest scores were included. Specifically, (1) indicators related to calvings resulting in live births and outliving each of the subsequent rearing periods; (2) indicators related to antimicrobial use (AMU) in calves as indicator for calf health; and (3) indicators related to herd health status.

To enable the development of a first draft of the KalfOK score, the experts divided a total of 100 points across the indicators $(5,10$, or 15 points per indicator). Key indicators that were perceived to have the highest association with quality of young stock rearing by the experts were allocated the most points and key indicators that were perceived less influential were assigned fewer points. For each of the indicators that were included in the KalfOK score, data-based threshold values such as the 90 th percentile were defined to decide whether a dairy herd did or did not receive a grade for a specific indicator. For example, one of the key indicators was the percentage of calves that outlived the rearing period between $56 \mathrm{~d}$ and $2 \mathrm{yr}$ old. The maximum amount of points a farmer could earn for this indicator was 10 points. If the percentage of calves that outlived the rearing period was above the defined threshold value, the herd received 10 points. Otherwise, no points were allocated to this key indicator.

The total sum of the grades of all individual key indicators provided a KalfOK score that could vary between 0 and 100 points, with a higher score associated with a higher quality of young stock rearing and a higher calf health status. The results of the expert workshop were discussed and optimized during an iterative process with a steering group with representatives of the Dutch Dairy organization (ZuivelNL) and farmer's organization [The Dutch Federation for Agriculture and Horticulture (LTO), The Hague, the Netherlands], the expert team, and participating farmers.

The KalfOK score was developed to provide an indication of the quality of young stock rearing on a quarterly basis. Thus, every quarter of the year each individual key indicator was evaluated and the number of points per indicator and the overall KalfOK score were calculated. In addition to the quarterly KalfOK score, in each quarter the moving average of the KalfOK score over the last year was calculated as the mean of the quarterly KalfOK scores of the last year to correct for seasonal fluctuations in several indicators (i.e., still births and mortality of young calves).

\section{Benchmark Values}

For each of the key indicators that were included in KalfOK, benchmark values were determined based on the mean of the total distribution for those indicators in the whole population of Dutch dairy herds. We requested permission to anonymously use census data from all Dutch dairy herds to compute benchmark values from the 4 nationally operating data collection organizations (RVO, Rendac, ZuivelNL, and GD) to determine the KalfOK score. The process to obtain agreement to use the data is described in detail in Santman-Berends et al. (2016). All variables that might link the data back to the original source were anonymized by an external encryption company (IntoFocus Data Transformation Services, Deventer, the Netherlands) before making the data available to the researchers. The same encryption code was used for all data sets to enable linking all data sets.

For each of the key indicators, minimum threshold values were determined with which the dairy herds had to comply to receive points. These threshold values were determined on (1) the results of the benchmark values and (2) expert consultancy. To evaluate 
whether the study population was representative for the Dutch dairy population, the overall KalfOK score was determined and compared between both the study population of 201 dairy herds and the whole Dutch dairy population using a median test in SAS 9.1.3 (SAS Institute Inc., Cary, NC).

\section{Validation of KalfOK}

Herd Health Checks. The validity KalfOK was evaluated by comparing the KalfOK score with the results of veterinarians that conducted a physical herd health check. This herd health check focused on the quality of calf and young stock rearing and health and welfare in 100 of the participating herds. To maximize the amount of variation in the validation sample, 25 herds with the lowest, 25 herds with the highest, and 50 herds with an average KalfOK score based on the prototype of KalfOK were selected. In case the selected herds outsourced the young stock rearing, the young stock rearing farm was visited and evaluated as well. All herd health checks were conducted in the period from December 2016 until March 2017 (winter period) by 3 veterinarians that were not otherwise involved in the project and were specialized in young stock. The selected herds were randomly allocated to 1 of the veterinarians who were blind to the KalfOK score of the herds. To ensure that the 3 veterinarians scored uniformly, standardized protocols were developed and optimized in collaboration with the 3 veterinarians. Two dairy herds were jointly visited under supervision of a veterinary expert of GD. During this visit, the developed protocol was tested, further standardized and optimized.

During the veterinary visits, the different age groups of calves were observed and scored (health, body, and skin condition, climate in the stable, hygiene of the stable, access and quality to feed and water). The scores were graded on a Likert-scale ranging from 1 (extremely inadequate) to 5 (excellent). Additionally, the veterinarians conducted a short questionnaire and requested complementary information from the farmer about the day-to-day management of the calves (calving management, colostrum supply, type and amount of feed). The questionnaire (in Dutch) can be requested by sending an email to the first author. Moreover, the veterinarians were requested to provide an overall score between 1 (extremely poor) and 10 (perfect) to summarize the total quality of young stock rearing. For this, the veterinarians were requested to provide an overall score for each of the 5 age categories of calves and young stock that were evaluated (i.e., calves $\leq 14 \mathrm{~d}$ old, calves 15-56 d old, calves $57 \mathrm{~d}$ to 3 mo old, calves $4-12$ mo old, and young stock $>1$ yr until moment of calving). Subsequently, the average of the 5 scores resulted in the total herd score. The results of the herd health checks were digitalized and combined using the program Survalyzer (Survalyzer, Utrecht the Netherlands) and SAS (SAS Institute Inc.).

Comparison Between the Herd Health Check and KalfOK. A principal component analysis in SAS (SAS Institute Inc.) was used to combine the results of the herd health checks into a limited number of factors. The different variables resulting from the herd health checks could be interpreted in the same manner, with higher scores being an indication for a better health and management according to the visiting veterinarian. All variables were combined into different factor variables that were retained when having an initial eigenvalue $\geq 1$ after rotation (Kaiser, 1960). Factors were rotated using varimax to simplify their structure and enhance interpretability while maintaining factor independence. The sum of factor scores resulted in a total score that was normally distributed and was associated with quality of young stock rearing. Herds with lower factor scores had lower observed young stock rearing quality and herds with higher total factor scores had higher observed young stock rearing quality. The association between the observed rearing quality (dependent variable) and the developed key indicators (independent variables) was assessed with multivariable linear regression analysis. Additionally, linear regression analysis was applied to assess differences in factor scores between the 3 veterinarians who performed the herd health checks correcting for the KalfOK score as a potential confounder.

The aim of KalfOK was to quantify the quality of young stock rearing based on routinely collected data enabling detection of herds with (1) an excellent quality of young stock rearing and (2) an insufficient quality of young stock rearing. Therefore, herds that belonged to the top or bottom $10 \%$ of the study population with respect to quality of young stock rearing were selected based on the overall herd health check score. The validity of KalfOK to detect herds with either an excellent or insufficient factor score in the herd health check was determined for different cutoff values of the moving average of the annual KalfOK score (i.e., 60, 65, 70, 80, 85 , and 90 points). Test characteristics of the KalfOK score, such as the sensitivity, specificity, and agreement, were calculated using the results from the herd health check as golden standard. Additionally, the Youden In$\operatorname{dex}(\mathrm{Y}=$ sensitivity + specificity -1$)$ was calculated to assess the cutoff value of the moving average of the annual KalfOK score that optimized classification of herds into groups. 


\section{Sensitivity Analysis}

Initially, a prototype of the KalfOK score was developed that was the result of the sum of scores of a limited number of key indicators. The validity of this prototype was evaluated by comparing the KalfOK scores with the overall factor score of the health check. Because KalfOK was partially developed based on expert opinion, we evaluated the sensitivity of the KalfOK score for (1) changing the key indicators, (2) changing the threshold values, (3) changing the amount of allocated points per key indicator, and (4) implementing binomial instead of ordinal scales for allocating points for key indicators. The alternatives within KalfOK were provided by the expert team, the stakeholders, or were based on the association between key indicators and the herd health check. Eventually, the sensitivity and specificity of more than 50 alternatives for KalfOK were evaluated. The sensitivity analysis with the highest effect on the appearance of the KalfOK system included (1) binomial grading (either grant points or not) versus an ordinal scale for part of the key indicators; (2) reallocation of grades when no animals were present in 1 or more of the age categories; and (3) applying different weights for the quarterly scores in the moving average of the annual KalfOK score, in which the quarterly KalfOK score in winter is weighed 2 times higher than in summer. Each of these 3 scenarios was conducted using different threshold values for grading points and was evaluated both singularly and in combination.

\section{KalfOK Score Development and Key Indicators for Individual Herds}

A KalfOK report presenting individual herd-level results obtained in KalfOK was created. The prototype of the report was optimized during an iterative process with the expert team, the stakeholders, and the participating farmers.

\section{RESULTS}

\section{Study Population}

In total, 201 dairy farmers participated in the development of KalfOK, from which 170 raised their own young stock and 31 outsourced the young stock rearing. From the 31 outsourced dairy herds, the data from the young stock rearing herd was also included in the development of KalfOK. In the period between January 1, 2014, and March 31, 2017, the average herd size of the study population was 110 cows $(>2 \mathrm{yr}$, median 99 cows). Per quarter of the year, on average, 28 calves were born and the average number of ear-tagged calves up to 1 yr old present in these herds was 26 .

Registrations in MediRund did not appear much different from the farmers reporting and seemed sufficiently complete to incorporate in KalfOK. The completeness of registrations of BVD vaccination was 28 MediRund registrations/37 farmer registrations, IBR vaccination (32/33), treatment of Cryptospirosis $(18 / 21)$, and treatment of coccidiosis $(17 / 21)$.

Eventually, 12 key indicators were included in KalfOK for which the farmer could receive points; additionally, 3 key indicators were included as informative parameters (Table 1). The key indicators included parameters on successful birth and rearing, AMU, and herd health status (Table 1). The vaccination status for BVD and IBR from MediRund were combined with the free status (data from GD Animal Health) for both infections. The key indicators treatment against coccidiosis, treatment against cryptospirosis, and closed farming system were included as informative parameters in KalfOK without grading them (Table 1).

\section{Cutoff and Benchmark Values}

The benchmark values for the 15 key indicators were calculated on data of all 17,159 Dutch dairy herds between January 1, 2014, and March 31, 2017. The threshold value for each key indicator was subsequently determined on the distribution in the census data combined with expert opinion. The percentage of calvings resulting in live births was graded 10 points when it was at least $92 \%$. The survival at birth was graded 15 points when the percentage was at least 95\% (Table 1). For the key indicators related to rearing of ear-tagged calves $<56 \mathrm{~d}$ old, the threshold values were set at a survival of at least $92 \%$ for 10 points and $97 \%$ for 15 points. The group of young stock ( $56 \mathrm{~d}$ to $2 \mathrm{yr}$ old) was graded when at least $98 \%$ survived. The threshold values for AMU were based on the 90th percentile of the defined daily dose of antibiotics per animal (farm level) $\left(\mathbf{D D D A}_{\mathbf{F}}\right)$ per quarter. Herd health indicators were graded based on the presence of a free or unsuspected illness or vaccination status. A BVD-free or -vaccinating herd received 6 points and 2 points were graded to an IBR-free or -vaccinating herd or a Salmonellaunsuspected herd (Table 1).

The median KalfOK score per quarter of the year was 76.6 (25th percentile $=68,75$ th percentile $=88$ points) in the 201 participating herds during the study period. The median annually moving KalfOK score in the study population was 77.0 points (25th percentile $=71,75$ th percentile $=85$ points; Figure 1a). In the total population of 17,159 Dutch dairy herds, the me- 
dian KalfOK score was 75.0 points $(25$ th percentile $=$ 65 , 75 th percentile $=87$ points), ranging from 0 to 100 points. The moving average of the annual KalfOK score for the total population was 75.1 points (25th percentile $=69,75$ th percentile $=83$ points; Figure $1 \mathrm{~b})$. The KalfOK scores of the study population were significantly higher than the score of the total population (median test, $P \leq 0.01$ ).
During the study period, the average annual moving KalfOK scores in all dairy herds slightly deteriorated from 75.5 points in the fourth quarter of 2014 to 74.7 points in the first quarter of 2017. In general, the quarterly scores showed a seasonal pattern, with lower scores in winter and higher scores in summer. The average KalfOK score per quarter was 53.9, 76.9, and 92.9 points for the $25 \%$ herds $(\mathrm{n}=4,290)$ with the lowest,

Table 1. Developed key indicators that were included in a young stock rearing quality system (KalfOK) with their definition, threshold and target value, maximum amount of points to be graded, and data source

\begin{tabular}{|c|c|c|c|c|}
\hline Key indicator & Definition & $\begin{array}{l}\text { Threshold and } \\
\text { target value }\end{array}$ & Points & Source \\
\hline \multicolumn{5}{|l|}{$\begin{array}{l}\text { Birth and rearing (ratio, } \\
\text { presented as percentage } \\
\text { per quarter) }\end{array}$} \\
\hline Live births & $\begin{array}{l}\text { The number of calves born alive in quarter i, divided by the } \\
\text { total number of calvings (alive and dead) in the same quarter }\end{array}$ & $\begin{array}{l}\geq 92.0 \\
\geq 95.0\end{array}$ & $\begin{array}{l}10 \\
15\end{array}$ & $\begin{array}{l}\text { Identification and } \\
\text { registration (I\&R), } \\
\text { Rendac (Son, the } \\
\text { Netherlands) }\end{array}$ \\
\hline $\begin{array}{l}\text { Successful rearing of } \\
\text { heifer calves } \leq 14 \mathrm{~d} \text { old }\end{array}$ & $\begin{array}{l}\text { The number of heifer calves alive at d } 14 \text { in quarter i, divided } \\
\text { by the number of ear-tagged heifer calves in the same quarter }\end{array}$ & $\begin{array}{l}\geq 92.0 \\
\geq 97.0\end{array}$ & $\begin{array}{l}10 \\
15\end{array}$ & $\mathrm{I} \& \mathrm{R}$ \\
\hline $\begin{array}{l}\text { Successful rearing of } \\
\text { calves } 15-56 \mathrm{~d} \text { old }\end{array}$ & $\begin{array}{l}\text { The number of calves alive at d } 56 \text { in quarter i, divided by the } \\
\text { number of calves between } 15 \text { and } 56 \mathrm{~d} \text { old corrected for the } \\
\text { calf days at risk in the same quarter }\end{array}$ & $\begin{array}{l}\geq 92.0 \\
\geq 97.0\end{array}$ & $\begin{array}{l}10 \\
15\end{array}$ & $\mathrm{I} \& \mathrm{R}$ \\
\hline $\begin{array}{l}\text { Successful rearing of } \\
\text { heifer calves } 56 \mathrm{~d} \text { to } \\
2 \mathrm{yr} \text { old }\end{array}$ & $\begin{array}{l}\text { The number of female cattle alive at } 2 \text { yr of age in quarter i, } \\
\text { divided by the number of female cattle between } 56 \mathrm{~d} \text { and } 2 \text { yr } \\
\text { old corrected for the animal days at risk in the same quarter }\end{array}$ & $\geq 98.0$ & 10 & $\mathrm{I} \& \mathrm{R}$ \\
\hline $\begin{array}{l}\text { AMU for treatment of } \\
\text { respiratory infections in } \\
\text { calves }<56 \mathrm{~d}\end{array}$ & $\begin{array}{l}\text { The defined daily dose animal (farm) }\left(\mathrm{DDDA}_{\mathrm{F}}\right) \text { of } \\
\text { antimicrobials applied in calves }(<56 \mathrm{~d}) \text { of which the effective } \\
\text { substance contain doxycycline, florfenicol, oxytetracycline, } \\
\text { tilmicosin, or tulathromycin }\end{array}$ & $\leq 1.70$ & 5 & $\begin{array}{l}\text { I\&R, MediRund } \\
\text { (ZuivelNL, The } \\
\text { Hague, the } \\
\text { Netherlands) }\end{array}$ \\
\hline $\begin{array}{l}\text { AMU for treatment of } \\
\text { diarrhea in calves }<56 \mathrm{~d}\end{array}$ & $\begin{array}{l}\text { The DDDA } \\
\text { which the effective substance contain amoxicillin/colistin, } \\
\text { colistin, paromomycin, trimethoprim/sulfadiazine, or } \\
\text { trimethoprim/sulfadoxine }\end{array}$ & $\leq 3.00$ & 5 & I\&R, MediRund \\
\hline $\begin{array}{l}\text { AMU for treatment of } \\
\text { other infections in } \\
\text { calves }<56 \mathrm{~d}\end{array}$ & $\begin{array}{l}\text { The DDDA } \\
\text { contain other antimicrobials applied in calves }(<56 \mathrm{~d}) \text { that } \\
\text { respiratory infections of diarrhea than those applied for }\end{array}$ & $\leq 3.10$ & 5 & I\&R, MediRund \\
\hline $\begin{array}{l}\text { AMU for treatment in } \\
\text { calves } 56 \mathrm{~d} \text { to } 1 \mathrm{yr} \text { old }\end{array}$ & The DDDA $_{F}$ of antimicrobials applied in calves ( $56 \mathrm{~d}$ to $1 \mathrm{yr}$ ) & $\leq 0.10$ & 5 & I\&R, MediRund \\
\hline Coccidiosis & Use of treatment for coccidiosis in the last $12 \mathrm{mo}$ & $\mathrm{NA}^{3}$ & NA & MediRund \\
\hline Cryptospirosis & Use of treatment for cryptospirosis in the last $12 \mathrm{mo}$ & NA & NA & MediRund \\
\hline Closed farming system & No cattle moved on-farm in the previous $12 \mathrm{mo}^{4}$ & NA & NA & $\mathrm{I} \& \mathrm{R}$ \\
\hline
\end{tabular}

${ }^{1}$ In the Netherlands, calves are not allowed to move off-farm until they are $14 \mathrm{~d}$ old resulting in the number of ear-tagged calves being a fair representative of the average number of calves corrected for the calf days at-risk.

${ }^{2} \mathrm{BVD}=$ bovine viral diarrhea; IBR = infectious bovine rhinotracheitis.

${ }^{3} \mathrm{NA}=$ not applicable.

${ }^{4}$ A combination of a dairy and a young stock rearing herd are considered one epidemiological unit and contacts between both herds are not regarded as on-farm movements. 
a)

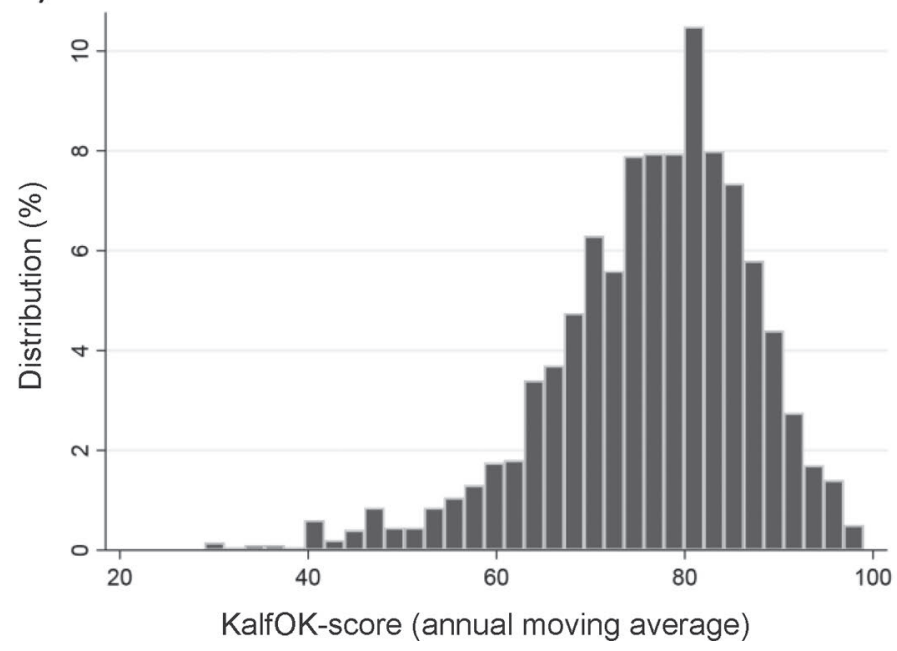

b)

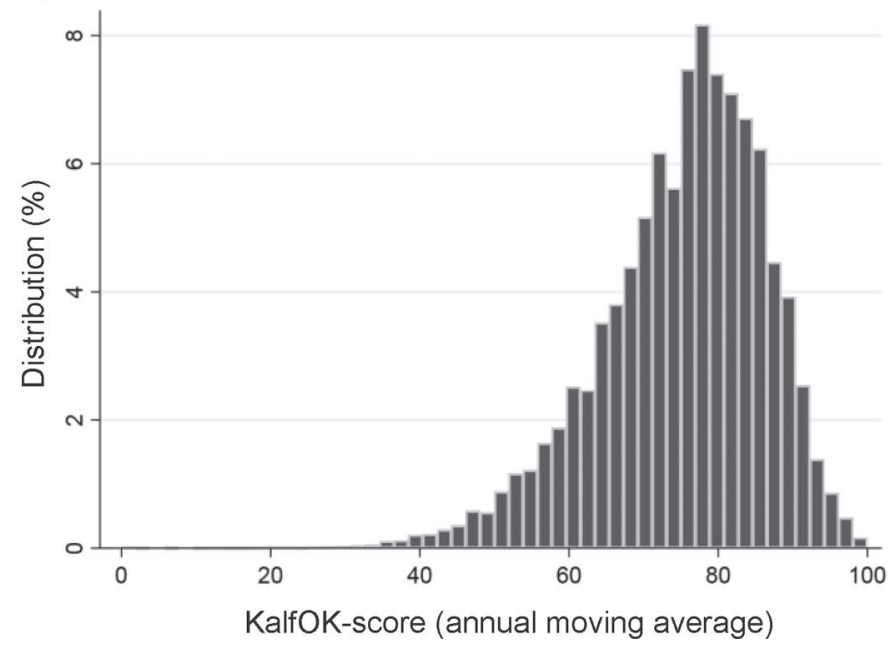

Figure 1. The distribution of the moving average of the annual young stock rearing quality system (KalfOK) score in (a) the study population of 201 Dutch dairy herds and (b) all 17,159 Dutch dairy herds from Jan. 1, 2014, to Mar. 31, 2017.

$50 \%$ herds $(\mathrm{n}=8,579)$ with an average, and $25 \%$ herds $(\mathrm{n}=4,290)$ with the highest KalfOK-score, respectively (Figure 2). The seasonal pattern was strongest in herds with the lowest scores and was almost absent in the herds with the highest quarterly KalfOK scores (Figure $2)$.

\section{Herd Health Checks}

In total, 113 of the study herds were visited (100 dairy herds and 13 young stock rearing herds) for a herd health check. Of the 100 dairy herds, 77 had cattle

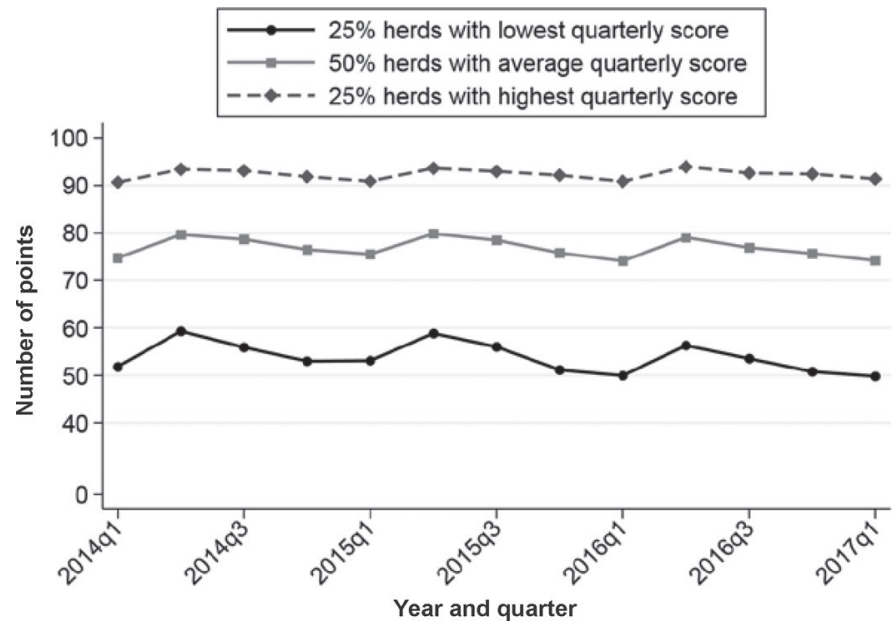

Figure 2. The average young stock rearing quality system (KalfOK) score per quarter for $25 \%$ herds with the highest, $50 \%$ herds with an average, and $25 \%$ herds with the lowest KalfOK score per quarter from Jan. 1, 2014, to Mar. 31, 2017. in all age groups and the herd health check comprised a complete impression of the quality of young stock rearing. The results of these 77 dairy herds were, therefore, initially used for evaluation of the validity of the KalfOK score. The herd characteristics, such as herd size, number of calvings, and the number of calves present in the 77 visited herds, were not significantly different from the herd characteristics of all 201 study herds.

From the 77 herds in which cattle were present in all age categories, 25 herds were visited by veterinarian A, 24 herds by veterinarian $\mathrm{B}$, and 28 herds by veterinarian $\mathrm{C}$. The quality of young stock rearing was graded on average 7.0 out of 10 points (median 7.4 points) and ranged from 3 to 10 . We found no significant differences in the grades between the 3 veterinarians (median $=$ $7.2,7.7$, and 7.7 points, respectively).

\section{Validity of KalfOK}

The multivariable model in which the 12 key indicators in KalfOK were included as independent variables explained $55.8 \%\left(\mathrm{R}_{2}=0.558\right)$ of the variation of the factor score of the herd health check. Five of the indicators included in KalfOK were significantly associated with the factor score. A higher percentage of calvings resulting in living calves, a higher successful rearing rate between $56 \mathrm{~d}$ and $2 \mathrm{yr}$ old, and a favorable BVD status were associated with a better score for young stock rearing. The AMU for diarrhea was associated with a lower score for rearing.

The validity of KalfOK to distinguish the top $10 \%$ dairy herds with supposedly an excellent quality of calf rearing and to detect the bottom 10\% dairy herds with 

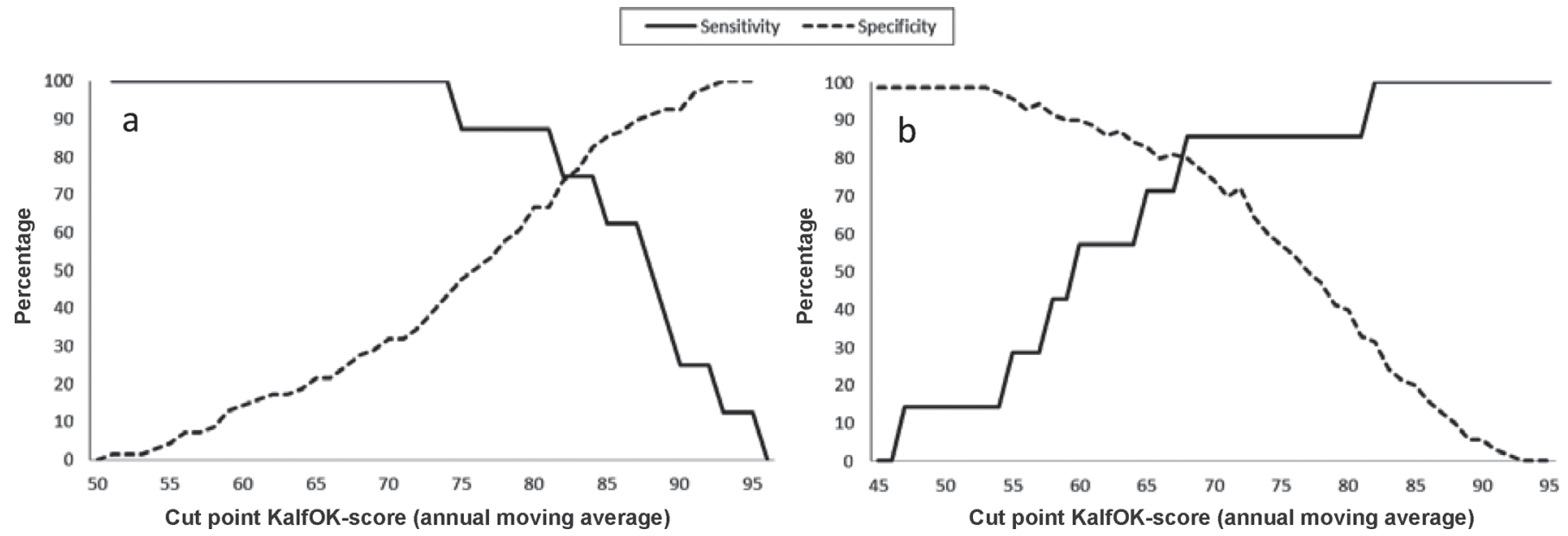

Figure 3. Plot of the sensitivity and specificity to detect herds with an excellent (a) or insufficient (b) quality of young stock rearing against various moving averages of the annual young stock rearing quality system (KalfOK) score.

supposedly an insufficient quality of calf rearing according to the herd health check is described in Figure 3. The moving average of the annual KalfOK score of the top $10 \%$ herds $(\mathrm{n}=8)$ with the highest observed quality of young stock rearing in the herd health checks ranged from 73 to 91 in the first quarter of 2017. Of these, 7 herds $(88 \%, 95 \%$ CI $=48-100 \%)$ scored at least 80 points and 5 herds $(63 \%, 95 \% \mathrm{CI}=24-91 \%)$ scored more than 85 points (Table 2 ). The herd with a KalfOK score of 73 had a lower score because the key indicators for successful young stock rearing up to $14 \mathrm{~d}$ (both bull and heifer calves) did not meet the threshold in the first quarter of 2017 (i.e., the mortality in this age category was too high). Additionally, the DDDA $F$ for respiratory infections in calves $<56 \mathrm{~d}$ old was above the threshold value. Historically, this specific herd also lost points for the key indicator for live births in several quarters.

The sensitivity of the initial version of KalfOK to distinguish herds with an excellent quality of young stock rearing was $88 \%(95 \% \mathrm{CI}=48-100 \%)$ with a specificity of $67 \%$ (95\% CI: $54-88 \%$ ) at a cutoff value of 80 points (Figure 3a and Table 2). At a cutoff value of 85 points, the sensitivity decreased to $63 \%(95 \%$ CI $=25-92 \%)$ with a specificity of $86 \%(95 \% \mathrm{CI}=75-93 \%$; Figure $3 \mathrm{a}$ and Table 2). The best cutoff value for detection of herds with an excellent quality of young stock rearing according to the Youden index was 80 points.

The moving average of the annual KalfOK score ranged from 47 to 82 points in the 7 herds with the lowest quality of young stock rearing according to the veterinarians. At a cutoff value of 75 points, 6 out of 7 herds with an insufficient quality of calf rearing were detected (sensitivity $=86 \%, 95 \% \mathrm{CI}=42-100 \%$ ). However, using this cutoff value, 28 out of 70 dairy herds were classified as having an insufficient quality of young stock rearing in KalfOK, whereas the quality was considered sufficient by the visiting veterinarians, which resulted in a specificity of $60 \%(95 \%$ CI $=48-72 \%$; Figure $3 \mathrm{~b}$ and Table 3 ). At a cutoff value of 70 , the sensitivity stayed the same whereas the specificity increased to $77 \%(95 \% \mathrm{CI}=66-86 \%)$. With the latter

Table 2. The validity of a young stock rearing quality system (KalfOK) to distinguish herds with an excellent young stock rearing quality in the first quarter of 2017 based on the herd health checks in 77 Dutch dairy herds

\begin{tabular}{|c|c|c|c|c|c|c|}
\hline \multirow[b]{2}{*}{$\begin{array}{l}\text { KalfOK } \\
\text { score }\end{array}$} & \multicolumn{2}{|c|}{$\begin{array}{c}\text { Observed quality of young stock rearing during herd } \\
\text { health check (veterinarian) }\end{array}$} & \multirow[b]{2}{*}{$\begin{array}{l}\text { Sensitivity }(\%) \\
\quad(95 \% \mathrm{CI})\end{array}$} & \multirow[b]{2}{*}{$\begin{array}{l}\text { Specificity }(\%) \\
\quad(95 \% \mathrm{CI})\end{array}$} & \multirow[b]{2}{*}{$\begin{array}{l}\text { Youden } \\
\text { index }\end{array}$} & \multirow[b]{2}{*}{$\begin{array}{l}\text { Agreement } \\
\quad(\%)\end{array}$} \\
\hline & $\begin{array}{c}\text { Average } \\
(90 \% \text { lowest factor score })\end{array}$ & $\begin{array}{c}\text { Excellent } \\
(10 \% \text { highest factor score })\end{array}$ & & & & \\
\hline$\geq 90$ points & 5 & 2 & 25.0 & 92.8 & 0.18 & 85.7 \\
\hline$<90$ points & 64 & 6 & $(3.2-65.1)$ & (83.9-97.6) & & \\
\hline$\geq 85$ points & 10 & 5 & 62.5 & 85.5 & 0.48 & 83.1 \\
\hline$<80$ points & 46 & 1 & $(47.3-99.7)$ & $(54.3-77.6)$ & & \\
\hline
\end{tabular}


Table 3. The validity of a young stock rearing quality system (KalfOK) to distinguish herds with an insufficient young stock rearing quality in the first quarter of 2017 based on the herd health checks in 77 Dutch dairy herds

\begin{tabular}{|c|c|c|c|c|c|c|}
\hline \multirow[b]{2}{*}{$\begin{array}{l}\text { KalfOK } \\
\text { score }\end{array}$} & \multicolumn{2}{|c|}{$\begin{array}{c}\text { Observed quality of youngstock rearing during herd } \\
\text { health check (veterinarian) }\end{array}$} & \multirow[b]{2}{*}{$\begin{array}{l}\text { Sensitivity }(\%) \\
\quad(95 \% \mathrm{CI})\end{array}$} & \multirow[b]{2}{*}{$\begin{array}{l}\text { Specificity }(\%) \\
\quad(95 \% \text { CI })\end{array}$} & \multirow[b]{2}{*}{$\begin{array}{l}\text { Youden } \\
\text { index }\end{array}$} & \multirow[b]{2}{*}{$\begin{array}{l}\text { Agreemen } \\
\quad(\%)\end{array}$} \\
\hline & $\begin{array}{c}\text { Insufficient } \\
(10 \% \text { lowest factor score })\end{array}$ & $\begin{array}{c}\text { Average } \\
(90 \% \text { highest factor score })\end{array}$ & & & & \\
\hline$<75$ points & 6 & 28 & 85.7 & 60.0 & 0.46 & 62.3 \\
\hline$\geq 75$ points & 1 & 42 & $(42.1-99.6)$ & $(47.6-71.5)$ & & \\
\hline$<70$ points & 6 & 16 & 85.7 & 77.1 & 0.63 & 77.9 \\
\hline$\geq 65$ points & 3 & 59 & $(18.4-90.1)$ & $(73.6-91.9)$ & & \\
\hline$<60$ points & 3 & 7 & 42.9 & 90.0 & 0.33 & 85.7 \\
\hline$>60$ points & 4 & 63 & $(9.9-81.6)$ & $(80.5-95.9)$ & & \\
\hline
\end{tabular}

cutoff value, the Youden index was highest $(0.63$, Table $3)$.

\section{Sensitivity Analysis}

All 100 dairy herds (including the 13 young stock rearing farms) that were visited were included in the sensitivity analysis in which points were reallocated when some age groups of animals were absent. Reallocation of points resulted in a lower sensitivity and specificity of the system to distinguish herds with an excellent status and to detect herds with an insufficient status (Table 4). The KalfOK score was not sensitive for applying higher weights on quarterly KalfOK scores in winter to detect herds with an insufficient quality of young stock rearing. The characteristics to distinguish herds with an excellent quality of calf rearing, how- ever, deteriorated (Table 4). Changing the ordinal to a binomial allocation of points resulted in an increased specificity and a higher agreement for detection of herds with an insufficient quality of young stock rearing. Nevertheless, the ability to correctly classify herds with an insufficient quality of young stock rearing (i.e., the sensitivity) decreased (Table 4).

\section{The KalfOK Report}

A KalfOK report was developed for each individual farmer with 4 separate areas presenting the herd-specific results (Figure 4 to 6 ; Table 5). In the first area (Figure 4), the herd-specific quarterly KalfOK-score and the moving average of the annual KalfOK score are presented for each of the quarters in the last $2 \mathrm{yr}$. The colors indicated whether the dairy herd belonged

Table 4. The validity of different alternatives for a young stock rearing quality system (KalfOK) to detect Dutch dairy herds with either an excellent or insufficient young stock rearing quality according to a herd health check in the first quarter of 2017

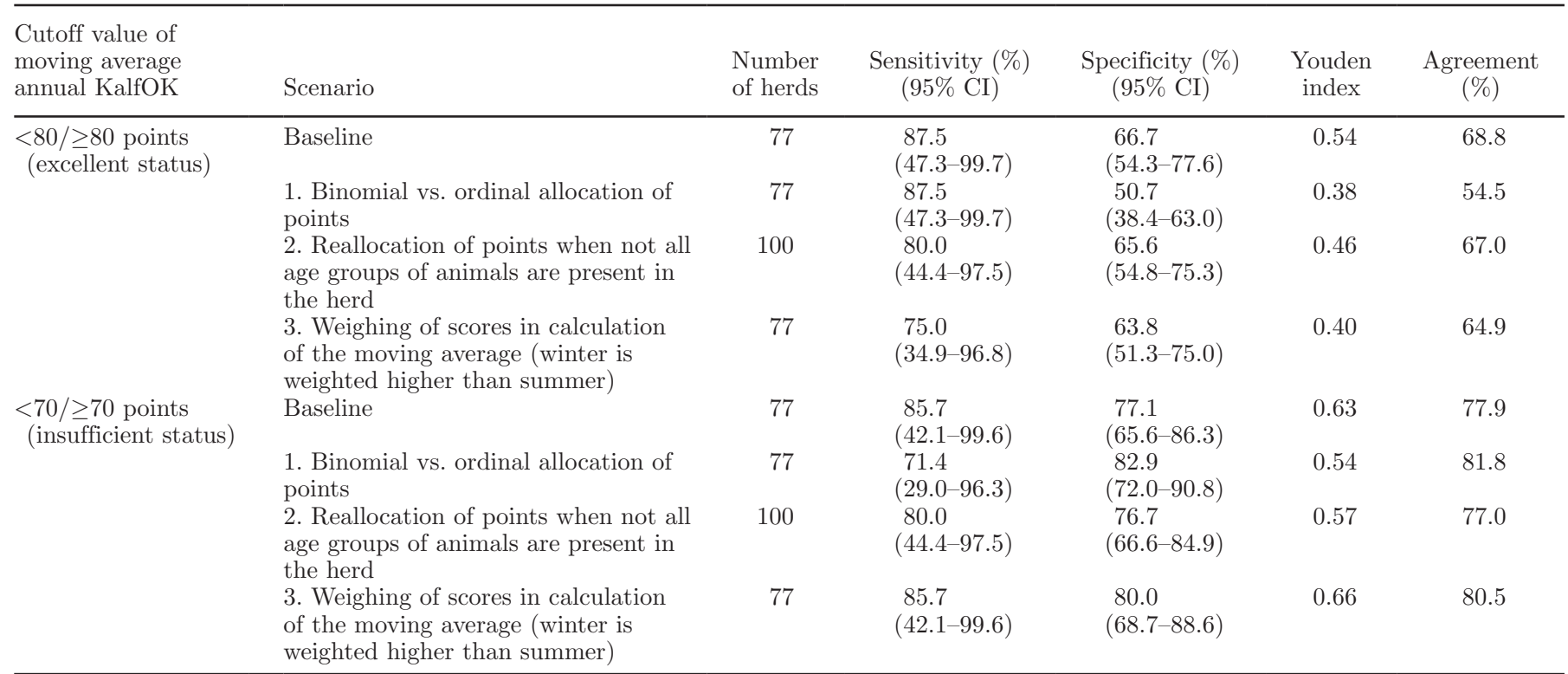


Table 5. The key indicators in a young stock rearing quality system (KalfOK) with the herd specific, benchmark, threshold and target values and whether the herd received points for each of the key indicator in the most recent quarter for an example herd

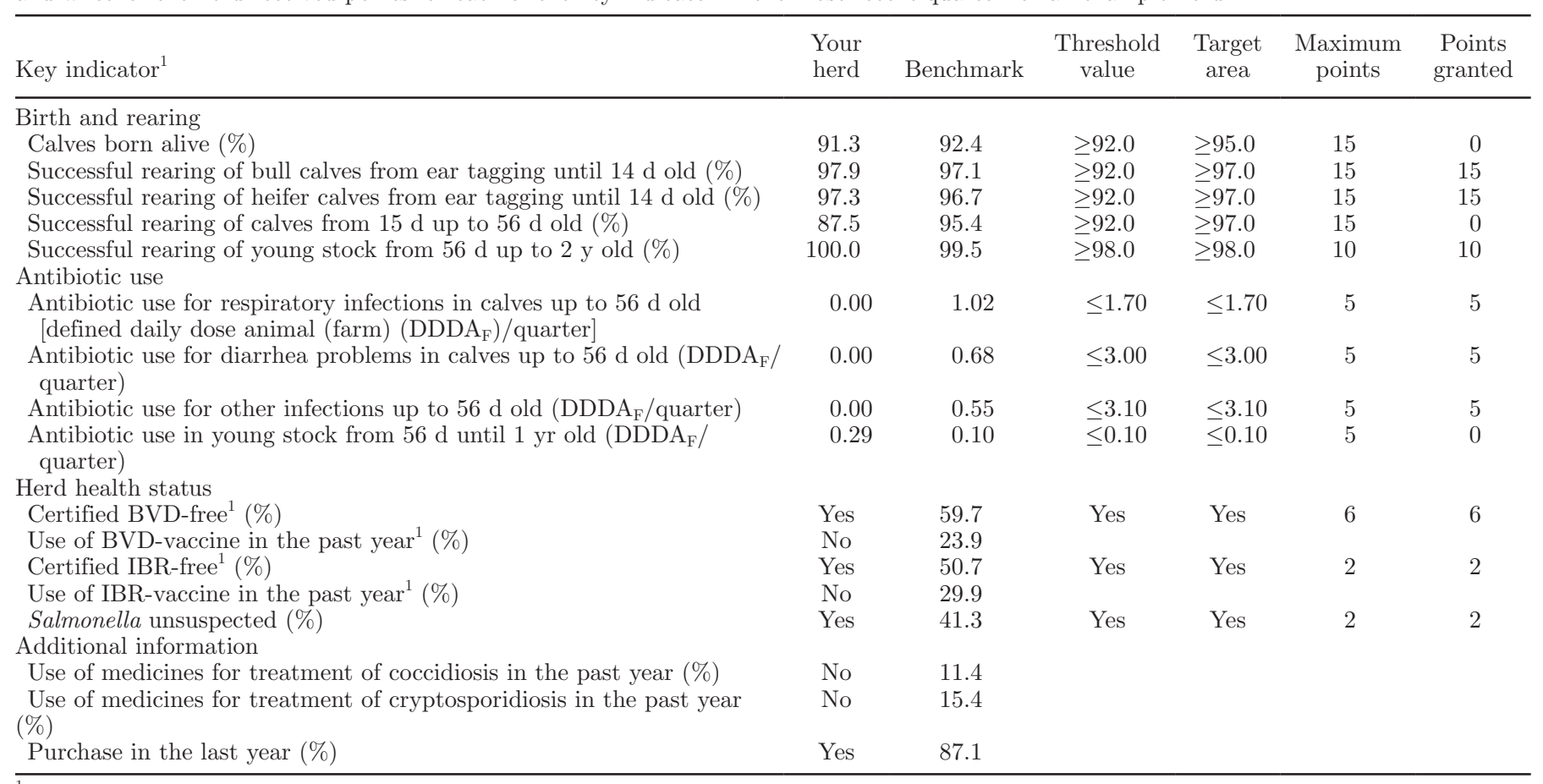

${ }^{1} \mathrm{BVD}=$ bovine viral diarrhea; IBR $=$ infectious bovine rhinotracheitis.

to the $25 \%$ of herds with the highest (light gray) or lowest (dark gray) scores. In the second area, the report lists both strengths and weaknesses of the specific herd, which can be used to guide management improvements (Figure 5).

In the third area, herd-specific quarterly values of each of the key indicators are presented for the last 2 yr. In Figure 6, the key indicator live births is displayed for an example herd. The number of calves that were included in the calculation of the key indicator is included in each bar. The farmers can use Table 5 to obtain the exact value and subsequent information of the key indicator in the first quarter of 2017.

\section{DISCUSSION}

The aim of our study was to develop a management tool to provide insight in the quality of young stock rearing of individual dairy farms. Insight can initiate awareness leading to improvement of animal health and welfare (Lam et al., 2017). A previous study showed that many farmers lack information about their herdspecific performance with regard to young stock rearing and calf mortality in the Netherlands (Santman-Berends et al., 2014). The KalfOK score will provide individual farmers with insight into their herd performance relative to other Dutch dairy herds. Subsequently, KalfOK will create awareness of strengths and weaknesses in the young stock rearing management. In this way, it is expected that implementation of this system will improve rearing practices and subsequent calf and young stock performance. Given that an optimal start as a calf may result in improved fertility, milk production, and durability in later life (Hultgren and Svensson, 2009), the gain of KalfOK may be tremendous. As a result of this study, KalfOK was implemented nationwide on

\begin{tabular}{|c|c|c|c|c|c|c|c|c|}
\hline & $\begin{array}{c}\text { Quarter } \\
2\end{array}$ & $\begin{array}{c}2015 \\
\text { Quarter } \\
3\end{array}$ & $\begin{array}{c}\text { Quarter } \\
4\end{array}$ & $\begin{array}{c}\text { Quarter } \\
1\end{array}$ & $\begin{array}{c}20 \\
\text { Quarter } \\
2\end{array}$ & $\begin{array}{l}16 \\
\text { Quarter } \\
3\end{array}$ & $\begin{array}{c}\text { Quarter } \\
4\end{array}$ & $\begin{array}{c}2017 \\
\text { Quarter } \\
1\end{array}$ \\
\hline Quarterly KalfOK-score & 65 & 80 & 82 & 62 & 90 & 75 & 80 & 65 \\
\hline Annually moving average & 73 & 74 & 76 & 72 & 79 & 77 & 77 & 78 \\
\hline
\end{tabular}

\begin{tabular}{|c|c|}
\hline & $25 \%$ highest score \\
\hline & $50 \%$ average score \\
\hline & $25 \%$ lowest score \\
\hline NA & not applicable \\
\hline
\end{tabular}

Figure 4. The young stock rearing quality system (KalfOK) quarterly and moving average of the annual KalfOK score (ranging from 0 to 100 points) for an example Dutch dairy herd. 


\section{Strong points and points for improvement:}

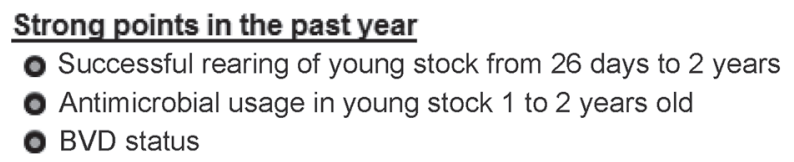

Points of attention

- Calves born alive

- Successful rearing calves 15 to 56 days old

- BVD status

Figure 5. The individual strengths (determined for the past year) and weaknesses (determined for the past quarter) for an example Dutch dairy herd. BVD = bovine viral diarrhea.

a voluntary basis from January 1, 2018, onward, and several Dutch dairy companies decided to stimulate the implementation of KalfOK by, for example, rewarding dairy herds with the best KalfOK scores. This has already resulted in more than $9,000(\approx 55 \%$ of the total Dutch dairy population) dairy farmers participating on a voluntary basis as of June 2018.

Data that are centrally registered can only provide a simplified indication of a herd's specific situation. The sensitivity analysis showed that the sensitivity of KalfOK decreased when reallocation of points was implemented in case missing age categories in the herd occurred; however, most points in KalfOK are allocated to the key indicators concerning rearing of calves $\leq 14$ $\mathrm{d}$ old (45 points for birth and rearing and part of the 15 points for AMU) or on herd level (10 points, herd health status). Therefore, in the development of the KalfOK system, the possibility was created to include data from young stock rearing farms combined with the data of the dairy herds for which they rear the calves. Dairy farmers that outsource young stock rearing may request their young stock rearing herd to join KalfOK so that data of the complete rearing period are available. An advantage of KalfOK is that it provides a continuous, objective, standardized comparison of quality of young stock rearing within and across all Dutch dairy herds without the need for herd visits. The benchmark values provide the opportunity to monitor the quality of rearing and calf health in all dairy herds.

For validation of the KalfOK score, 100 of the 200 participating herds were selected based on their performance in the initial KalfOK score. This was done to maximize the variability in quality of young stock rearing, but may have resulted in a slight overestimation of the systems performance. Herds with an extremely high or low score are probably easier to identify during the herd health check than herds with scores close to the cutoff values. Nevertheless, it was most important

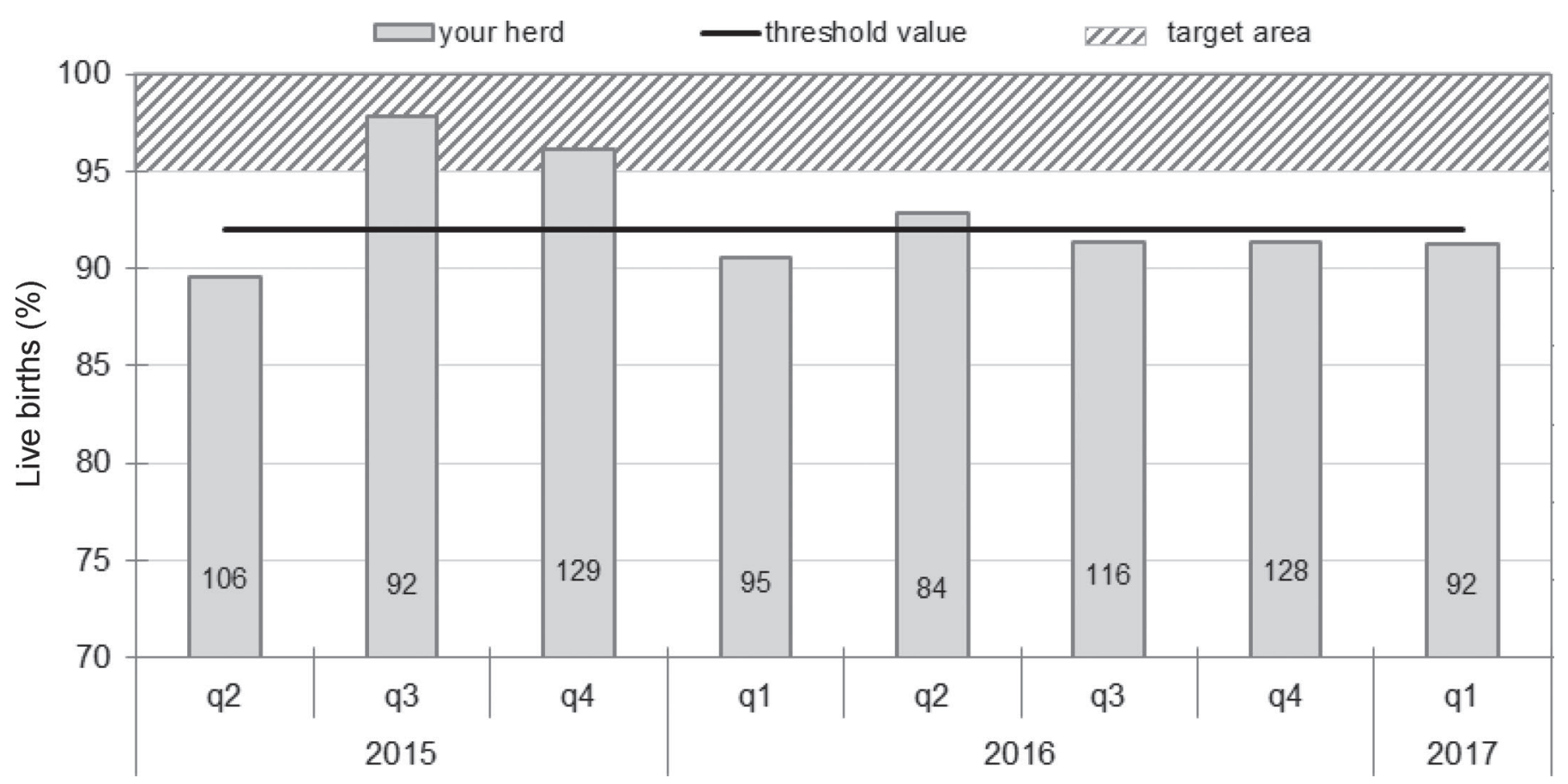

Figure 6. The key indicator live births per quarter for the past $2 \mathrm{yr}$ with the threshold value and target area for an example herd. The numbers in the bars present the number of calves born in each quarter. 
to evaluate the validity of the system to distinguish herds with excellent young stock rearing and to detect herds with insufficient young stock rearing. Therefore, it was important to select extreme herds for a herd health check, and the probability to include such herds was assumed highest using this method of selection. In 23 of the selected herds, no animals were present in the minimum of the age categories, resulting in a lessoptimal calculation of the KalfOK score. Nevertheless, we decided to include these herds in the validation even though at least 1 of the age groups was empty because this is reality and enables a representative evaluation of the validity of KalfOK.

Although the validity of KalfOK was satisfactory, situations did occur where the veterinarian scored the quality of young stock rearing different from KalfOK. In general, KalfOK appeared stricter than the qualification of the veterinarian. When a cutoff value of 70 points was applied in KalfOK, the quality of young stock rearing in 17 herds was believed sufficient by the veterinarian but insufficient in KalfOK. These herds often failed points for the key indicator live births, an indicator that is less visible for the veterinarian during a single visit. In the single case that the veterinarian classified the quality of young stock rearing as excellent whereas the herd scored below 75 points in KalfOK, the herd had a high mortality rate in young calves. Even though the rearing management in this herd appeared to be of high quality during the visit, high mortality rates showed the contrary and KalfOK seems to provide a better indication of the quality of young stock rearing than the single veterinary visit in this specific case. Part of the differences between the qualification of the veterinarian and KalfOK may be explained by the fact that the veterinarian only visited the herd once, whereas KalfOK is based on continuous data. Likewise, human observations can be subjective; therefore, we jointly visited 2 herds and tried to reach concordance about the definition of high and low scores for rearing quality. Nevertheless, 2 herds may not have been sufficient to prevent subjectivity completely. This human subjectivity is often the greatest challenge in systems in which animal health and welfare is determined based on physical herd health inspections (Holzhauer et al., 2006). Therefore, objective and standardized scoring systems with information that can be used to improve animal health and welfare are to be supported and are increasingly implemented (Bartussek, 1999; Scott et al., 2001; Bracke et al., 2002; Botreau et al., 2007; Brouwer et al., 2015).

A previous Dutch study (unpublished data, GD Animal Health, Deventer, the Netherlands) showed that more than $80 \%$ of the dairy herds sporadically have a high calf mortality (belonging to the $25 \%$ of the dairy herds with the highest calf mortality), which would result in a very low KalfOK score for that specific quarter. The aim of KalfOK is to evaluate and monitor the quality of young stock rearing and incidental problems that can occur regardless the quality of management are of minor interest. Therefore, a moving average KalfOK score that was based on the mean value of the quarterly scores of the last year was chosen to classify herds. Advantages of the moving average of the annual KalfOK score are that it remains more stable throughout, is not influenced by seasonal patterns, and is less sensitive to incidents. Drawback of the moving average of the annual KalfOK score is that it will take some time to show improvement in rearing management.

Within KalfOK, 10 points were allocated for the herd health status. These points were unequally divided over the herd health status for Salmonella, IBR, and BVD, with 2 points for a favorable status for the first 2 and 6 points for a favorable BVD status. This was based on the results of the multivariable linear model, in which the BVD status had the strongest association with the observed quality of young stock rearing. Additionally, 3 key indicators - treatment status for coccidiosis, treatment status for cryptosporidiosis, and having a closed farming system-were only included as informative indicators and were not allocated any points. For treatment status, no points were graded because not treating these specific infections could mean either there was no infection (favorable) or the infection was not treated by the farmer (unfavorable). With regard to having a closed farming system, it is known that purchase is an important risk factor for introduction of diseases in a herd (Van Schaik et al., 2002). Nevertheless, the exact risk is highly dependent on the herd health status in the herd of origin of the purchased animal and the risk-mitigating measures (i.e., tests or vaccination) taken before a new animal is introduced in the herd. This information is not centrally registered and it was therefore decided not to grade this key indicator but to provide the herd result and corresponding benchmark value on an informative basis. Additionally, the risk will differ greatly with the number and type of cattle introduced. All 3 factors that were included as informative parameters can have unfavorable effects manifesting in a deterioration in some of the other key indicators, indirectly resulting in a reduced KalfOK score.

The KalfOK system should be revalidated after a few years to keep the system up to date because changes in the Dutch dairy industry, such as further reduction in AMU, may influence the association between the quality of rearing management and calf health. Although KalfOK was developed for the dairy industry in the Netherlands, a similar tool might also be conceivable 
for livestock production system in other countries. An increasing amount of automatically collected animal and herd-specific data are available. Obtaining access to all this information and subsequently transferring it to objective and easy interpretable information for farmers is challenging. Nevertheless, combining different types and sources of data into informative tools, such as KalfOK, can result in tremendous added value for individual farmers because of increased awareness. Subsequently, implementation of such tools also provides potential for both herd-specific and nationwide monitoring of animal health. The information in this paper might therefore be valuable for those who want to develop a similar quality system.

\section{CONCLUSIONS}

The KalfOK system provides an indication of the quality of young stock rearing and subsequent calf health for individual famers and is able to distinguish between herds with an excellent and insufficient quality of young stock rearing. The tool offers farmers insight in their herd-specific strengths and weaknesses in rearing management and may stimulate improvement.

\section{ACKNOWLEDGMENTS}

This study was financed by the producer organization for dairy (ZuivelNL, The Hague, the Netherlands). We acknowledge all farmers, veterinarians, and stakeholders [Dutch Federation of Agriculture and Horticulture (LTO), The Hague, the Netherlands; The Dutch Dairy Association (NZO), The Hague, the Netherlands; Sustainable Dairy Association (DZK), The Hague, the Netherlands] that participated in the development of KalfOK.

\section{REFERENCES}

Bartussek, H. 1999. A review of the animal needs index (ANI) for the assessment of animals' well-being in the housing systems for Austrian proprietary products and legislation. Livest. Prod. Sci. 61:179-192.

Botreau, R., M. Bonde, A. Butterworth, P. Perny, M. B. Bracke, J. Capdeville, and I. Veissier. 2007. Aggregation of measures to produce an overall assessment of animal welfare. Part 1: A review of existing methods. Animal 1:1179-1187.

Bracke, M. B. M., B. M. Spruijt, J. H. M. Metz, and W. G. P. Schouten. 2002. Decision support system for overall welfare assess- ment in pregnant sows. A model structure and weighting procedure. J. Anim. Sci. 80:1819-1834.

Brouwer, H., J. A. Stegeman, J. W. Straatsma, G. A. Hooijer, and G. Van Schaik. 2015. The validity of a monitoring system based on routinely collected dairy cattle health data relative to a standardized herd check. Prev. Vet. Med. 122:76-82.

de Vries, M., E. A. M. Bokkers, T. Dijkstra, G. Van Schaik, and I. J. M. De Boer. 2011. Invited review: Association between variables of routine herd data and dairy cattle welfare indicators. J. Dairy Sci. 94:3213-3228.

Ettema, J. F., and J. E. P. Santos. 2004. Impact of age at calving on lactation, reproduction, health and income in first-parity Holsteins on commercial farms. J. Dairy Sci. 87:2730-2742.

Holzhauer, M., C. J. Bartels, B. Van den Borne, and G. Van Schaik. 2006. Intra-class correlation attributable to claw trimmers scoring common hind-claw disorders in Dutch dairy herds. Prev. Vet. Med. $75: 47-55$.

Hultgren, J., and C. Svensson. 2009. Heifer rearing conditions affect length of productive life in Swedish dairy cows. Prev. Vet. Med. $89: 255-264$.

Kaiser, H. F. 1960. The application of electronic computers to factor analysis. Educ. Psychol. Meas. 20:141-151.

Kelly, P. C., S. J. More, M. Blake, I. Higgins, T. Clegg, and A. Hanlon. 2013. Validation of key indicators in cattle farms at high risk of animal welfare problems: A qualitative case-control study. Vet. Rec. 172:314-318.

Lam, T. J. G. M., J. Jansen, and R. J. Wessels. 2017. The RESET Mindset Model applied on decreasing antibiotic usage in dairy cattle in the Netherlands. Ir. Vet. J. https://doi.org/10.1186/s13620 $-017-0085-x$.

Ortiz-Pelaez, A., D. G. Prittchard, D. U. Pfeiffer, E. Jones, P. Honeyman, and J. J. Mawdsley. 2008. Calf mortality as a welfare indicator on British cattle farms. Vet. J. 176:177-181.

Sandgren, C. H., A. Lindberg, and L. J. Keeling. 2009. Using a national dairy database to identify herds with poor welfare. Anim. Welf. 18:523-532.

Santman-Berends, I. M. G. A., H. Brouwer-Middelesch, L. Van Wuijckhuise, A. J. G. De Bont-Smolenaars, and G. Van Schaik. 2016. Surveillance of cattle health in the Netherlands: monitoring trends and 1 developments using routinely collected bovine census data. Prev. Vet. Med. 134:103-112.

Santman-Berends, I. M. G. A., M. Buddiger, A. J. Smolenaars, C. D. Steuten, C. A. Roos, A. J. Van Erp, and G. Van Schaik. 2014. A multidisciplinary approach to determine factors associated with calf rearing practices and calf mortality in dairy herds. Prev. Vet. Med. 117:375-387.

Scott, E. M., A. M. Nolan, and J. L. Fitzpatrick. 2001. Conceptual and methodological issues related to welfare assessment: a framework for measurement. Acta. Agric. Scand. A Anim. Sci. 30:5-10.

Seppä-Lassila, L., K. Sarjokari, M. Hovinen, T. Soveri, and M. Norring. 2016. Management factors associated with mortality of dairy calves in Finland: A cross sectional study. Vet. J. 216:164-167.

Van Eetvelde, M., and G. Opsomer. 2017. Innovative look at dairy heifer rearing: Effect of prenatal and post-natal environment on later performance. Reprod. Domest. Anim. 52:30-36.

Van Schaik, G., Y. H. Schukken, M. Nielen, A. A. Dijkhuizen, H. W. Barkema, and G. Benedictus. 2002. Probability of and risk factors for introduction of infectious diseases into Dutch SPF dairy farms: a cohort study. Prev. Vet. Med. 54:279-289. 